\title{
Pendidikan lingkungan berbasis experiential learning untuk meningkatkan literasi lingkungan
}

\author{
Riza Sativani Hayati \\ Universitas Muhammadiyah Makassar, Indonesia \\ Email: rizasativani.hayati@unismuh.ac.id
}

\begin{abstract}
Abstrak
Kerusakan ekosistem dan penurunan jumlah biodiversitas terus berlanjut. Kerusakan ekosistem akibat aktivitas manusia telah menjadi permasalahan dunia. Aktivitas merusak tersebut mencerminkan rendahnya literasi lingkungan masyarakat. Pendidikan lingkungan dapat menjadi solusi untuk meningkatkan literasi lingkungan masyarakat. Tujuan dari pendidikan lingkungan yaitu (1) awareness; (2) knowledge; (3) attitude; (4) skills; (5) partisipation. Salah satu metode efektif dalam pendidikan lingkungan adalah dengan berbasis experiential learning. Artikel ini bertujuan memaparkan konsep pendidikan lingkungan berbasis experiential learning yang dapat menjadi salah satu alternatif integrasi pendidikan lingkungan di sekolah. Dalam artikel ini dibahas mengenai urgensi literasi lingkungan, bagaimana pendidikan lingkungan mampu meningkatkan literasi lingkungan, dan konsep detail bagaimana melaksanakan pendidikan lingkungan berbasis experiential learning di sekolah. Pendidikan lingkungan berbasis experiential learning berarti menanamkan siklus belajar Kolb dalam pembelajaran dan program pendidikan lingkungan. Siklus Kolb terdiri atas: (1) Concrete Experience; (2) Observation and Reflection; (3) Forming Abstract Concept; (4) Testing in New Situation. Pendidikan lingkungan berbasis experiential learning akan
\end{abstract}


memberikan bekal bagi siswa untuk dapat merancang tindakan pro-lingkungan atau berpartisipasi dalam memberikan solusi permasalahan lingkungan.

Kata Kunci: Pendidikan Lingkungan, Experiential Learning, Literasi Lingkungan

\begin{abstract}
Damage to the ecosystem and decline in the amount of biodiversity continues. Ecosystem damage due to human activities has become a global problem. This destructive activity reflects the low of the community's environmental literacy. Environmental education can be a solution to improve community's environmental literacy. The objectives of environmental education are (1) awareness; (2) knowledge; (3) attitude; (4) skills; and (5) participation. One effective method in environmental education is based on experiential learning. This article aims to explain the concept of environmental education based on experiential learning which can be an alternative integration of environmental education in schools. This article discusses the urgency of environmental literacy, how environmental education can improve environmental literacy, and detailed concepts of how to implement environmental education based on experiential learning in schools. Experiential learning-based environmental education means instilling Kolb's learning cycle in learning and environmental education programs. The Kolb cycle consists of: (1) Concrete Experience; (2) Observation and Reflection; (3) Forming Abstract Concept; (4) Testing in New Situation. Experiential learning based environmental education will provide provisions for students to be able to design pro-environment actions or participate in providing solutions to environmental problems.
\end{abstract}

Keywords: Environmental Education, Experiential Learning, Environmental Literacy

\title{
Pendahuluan
}

Indonesia merupakan negara maritim dengan keanekaragaman organisme yang menunjukkan keseluruhan variasi gen, jenis, dan ekosistem (biodiversitas) yang luar biasa. Indonesia mendapatkan julukan sebagai episentrum biodiversitas dunia (Stehli \& Wells, 2014. Indonesia memiliki 19 tipe ekosistem alami tersebar dari Sumatera sampai Papua. Keanekaragaman tumbuhan Indonesia mencapai 110.483 spesies, biota perairan laut Indonesia 
berkisar 6.396 spesies, fauna endemis 270 spesies mamalia, 386 spesies burung, 328 spesies reptil, 204 spesies amphibia, dan 280 jenis ikan (BAPPENAS, 2016).

Kerusakan ekosistem dan penurunan jumlah biodiversitas terus berlanjut. Sebagai contoh, kerusakan laut akibat aktivitas manusia telah menjadi permasalahan dunia. Diperkirakan 150 juta ton plastik terakumulasi di laut dunia (Tessnow-von Wysocki \& Le Billon, 2019)reward compliance and deter non-compliance among the parties to the agreement. The design process can also positively affect interactions between states and help shift national perspectives and interests during negotiations. Based on treaty design evaluations of the Montreal and Kyoto Protocols, a review of existing measures to curb plastics at sea, and expert interviews, this study identifies seven treaty design elements likely to improve the success of a future legally binding mechanism to address marine plastic pollution. These include: a. Di Makassar, Sulawesi Selatan sendiri telah ditemukan microplastik dalam ikan (Purba et al., 2019). Aktivitas lain yang merusak laut antara lain illegal fishing (Arianto, 2017), pengambilan terumbu karang untuk bangunan (Uar, Murti, \& Hadisusanto, 2016), dan aktivitas wisatawan bahari seperti diving dan snorkeling. Aktivitas merusak tersebut masih mencerminkan rendahnya literasi lingkungan kelautan masyarakat. Salah satu penyebab rendahnya literasi lingkungan adalah kurangnya edukasi lingkungan kelautan kepada masyarakat untuk menjaga ekosistem laut. Edukasi lingkungan kelautan ini dapat dilakukan salah satunya dengan memberikan aktivitas pendidikan lingkungan.

Pendidikan lingkungan adalah salah satu cara mengatasi illiterasi lingkungan. Literasi lingkungan merupakan tantangan utama dalam melindungi ekosistem, melakukan edukasi tentang pentingnya ekosistem yang sehat sangat penting bagi perlindungan ekosistem (Bjorkland \& Pringle, 2001). Salah satu metode efektif dalam pendidikan lingkungan adalah dengan mengaplikasikan experiential learning. Pendidikan berbasis pengalaman di lapangan penting untuk disiplin ilmu perilaku, ekologi, evolusi, sistematika, sains, dan ilmu konservasi (Fleischner et al., 2017). Pendidikan berbasis pengalaman memaksa peserta didik untuk mempertanyakan dan mengevaluasi kembali asumsi mereka tentang bagaimana dunia alami beroperasi (Aman, Sudrajat, Yuliana, 2018). Peserta didik akan memiliki kesempatan lebih besar untuk memupuk koneksi kritis dari konsep abstrak menjadi realitas nyata. Hal ini akan memberikan dampak positif bagi peserta didik untuk memiliki kemampuan mengambil keputusan dan bertindak ramah lingkungan, minimal peserta didik akan lebih terhadap lingkungan agar bersih dan sehat. 


\section{Pembahasan dan Pembahasan}

\section{Urgensi Literasi Lingkungan}

Kerusakan lingkungan di Indonesia menunjukkan illiterasi lingkungan masyarakat pengguna lingkungan. BAPPENAS menyampaikan terdapat tiga faktor yang menyebabkan kerusakan alam, yaitu kegiatan manusia, pemilihan teknologi, dan struktural lembaga (BAPPENAS, 2004). Faktor kegiatan manusia yang merusak lingkungan antara lain: (1) kesadaran, pemahaman, dan kepedulian masyarakat yang rendah; (2) pemanfaatan berlebih; (2) pemungutan dan perdagangan ilegal; (3) konversi habitat alami; (4) monokulturisme dalam budidaya dan pemanfaatan; (5) tekanan penduduk; dan (6) kemiskinan dan keserakahan. BAPPENAS menempatkan rendahnya kesadaran dan kepedulian masyarakat terhadap lingkungan nomor satu di antara faktor lain. Sebagian masyarakat kurang memiliki kesadaran dan pemahaman tentang makna penting keanekaragaman hayati bagi kehidupan sehari-hari maupun sebagai aset pembangunan. Pemahaman yang kurang ini menimbulkan sikap tidak peduli yang mengarah pada perusakan. Hal ini menunjukkan bahwa masyarakat Indonesia masih belum memiliki literasi lingkungan atau illiterasi terhadap lingkungan. Literasi lingkungan pada masyarakat sangat diperlukan dalam rangka memelihara keberlanjutan lingkungan.

The Campaign for Environmental Literacy (2011) dalam (RIEEA, 2016) menjelaskan definisi literasi lingkungan yaitu kapasitas individu untuk bertindak dengan sukses dalam kehidupan sehari-hari dengan pemahaman yang luas tentang bagaimana individu maupun masyarakat saling berhubungan satu sama lain termasuk dengan sistem alam, serta bagaimana mereka dapat melakukannya secara berkelanjutan. Ini membutuhkan kesadaran, pengetahuan, keterampilan, dan sikap yang memadai untuk mempertimbangkan lingkungan dalam keputusan sehari-hari tentang konsumsi, gaya hidup, karier, dan kewarganegaraan, dan untuk terlibat dalam aksi lingkungan, baik secara individu dan kolektif. Berdasarkan pengertian di atas, komponen literasi lingkungan dapat ditafsirkan menjadi empat, yaitu pengetahuan ekologis, mempengaruhi (misalnya sikap pro-lingkungan, sensitivitas lingkungan, self efficcacy), keterampilan kognitif (misalnya analisis masalah dan penyelesaian masalah), dan perilaku lingkungan (Szczytko, Stevenson, Peterson, Nietfeld, $\&$ Strnad, 2018)particularly when little time is available for evaluation. Since environmental literacy (EL. 
Salah satu upaya untuk menanamkan literasi lingkungan adalah melalui integrasi pendidikan lingkungan di sekolah, baik secara cocurriculer maupun extracurricular. The Campaign for Environmental Literacy (2011) dalam (RIEEA, 2016) menyebutkan lima komponen penting yang mencerminkan pembelajaran kemanusiaan dan kewarganegaraan: (1) Kapasitas untuk bertindak secara pribadi dan kolektif dan partisipasi masyarakat; (2) Keterampilan memecahkan masalah dan berpikir kritis; (3) Sikap penghargaan dan kepedulian terhadap lingkungan; (4) Pengetahuan dan pemahaman tentang sistem dan proses manusia dan alam; dan (5) Kesadaran tentang hubungan antara lingkungan dan kehidupan manusia. Pendidikan lingkungan kyang baik adalah yang mampu mengarahkan peserta didik memiliki literasi lingkungan dengan memperhatikan komponen di atas.

Kemitraan untuk Keterampilan Abad 21 (RIEEA, 2016) mendefinisikan siswa yang memiliki literasi lingkungan atau melek lingkungan sebagai siswa yang mampu untuk:

1. Menunjukkan pengetahuan dan pemahaman tentang lingkungan dan faktor yang mempengaruhinya, terutama yang berkaitan dengan udara, iklim, tanah, makanan, energi, air dan ekosistem;

2. Menunjukkan pengetahuan dan pemahaman tentang dampak penduduk terhadap alam (misalnya pertumbuhan populasi, tingkat konsumsi sumber daya, dll.);

3. Menyelidiki dan menganalisis masalah lingkungan, kemudian membuat kesimpulan akurat tentang solusi yang efektif; dan

4. Mengambil tindakan individu dan kolektif untuk mengatasi tantangan lingkungan, misalnya berpartisipasi dalam aksi global atau memberikan tindakan solusi terhadap permasalahan lingkungan.

\section{Pendidikan Lingkungan untuk Literasi Lingkungan}

Istilah pendidikan lingkungan muncul pada Tahun 1960-an sebagai gerakan lingkungan yang pada waktu itu memperhatikan kualitas udara dan air (polusi), pertumbuhan populasi dunia, terus menipisnya sumber daya alam dan degradasi lingkungan (Gough, Annette, and Gough, 2015). Definisi awal bertujuan menghasilkan warga negara yang memiliki pengetahuan tentang lingkungan biofisik dan masalahnya, menyadari bagaimana menyelesaikan masalah dan termotivasi untuk menjadi problem solver. Akar pendidikan 
lingkungan di Amerika Serikat ini adalah pendidikan konservasi dan filosofi pendidikan progresif liberal, misalnya, John Dewey.

Pendidikan lingkungan merupakan salah satu cara mengatasi illiterasi lingkungan. Illiterasi lingkungan merupakan tantangan utama dalam melindungi ekosistem, melakukan edukasi tentang pentingnya ekosistem yang sehat sangat penting bagi perlindungan ekosistem (Bjorkland \& Pringle, 2001). International Environment and School Initiative (CERI 1995) sebagai lembaga di bawah Organization for Economic Cooperation and Development (OECD) telah menyampaikan beberapa langkah untuk mengatasi illiterasi lingkungan, antara lain dengan reformasi kebijakan pendidikan, pengembangan pendidik yang profesional, penelitian, revisi kurikulum untuk membangun perspektif lingkungan, kemitraan antara masyarakat dengan lembaga pendidikan, dan pengembangan metodologi pengajaran untuk meningkatkan kualitas dan relevansi pendidikan (Bjorkland \& Pringle, 2001). Asosiasi Amerika Utara untuk Pendidikan Lingkungan (2017) dalam (Szczytko et al., 2018)particularly when little time is available for evaluation. Since environmental literacy (EL menyampaikan bahwa tujuan dari pendidikan lingkungan adalah untuk membangun literasi lingkungan.

Tujuan dari pendidikan lingkungan tidak hanya pengetahuan lingkungan saja, sekolah biasanya gagal menerjemahkan dan mengimplementasikan ini. Ada lima tujuan dari program pendidikan lingkungan (Granit-Dgani, Kaplan, \& Flum, 2017) yang mencakup pembelajaran, motivasi, dan pembentukan identitas seperti: (1) mempromosikan relevansi yang dirasakan siswa dari konten lingkungan; (2) memfasilitasi rasa tanggung jawab pribadi dan kolektif siswa untuk sustainability atau keberlanjutan; (3) meningkatkan pengetahuan siswa tentang konten lingkungan; (4) meningkatkan kesiapan siswa untuk aksi lingkungan; dan (5) memulai eksplorasi pertanyaan seputar lingkungan. Sedangkan Water Monitoring Youth Portal (Portal, n.d.) menyampaikan ada lima tujuan dari pendidikan lingkungan, yaitu (1) awareness atau kesadaran pada kepercayaan dan sikap; (2) knowledge atau pengetahuan; (3) attitude atau sikap; (4) skills atau keterampilan; (5) partisipation atau partisipasi.

Pendidikan lingkungan harus menyertakan pengembangan critical thinking skills. Critical thinking dalam pendidikan lingkungan didefinisikan dengan: (1) menggambarkan inti dari konsep dan menunjukkan area yang dicakup konsep; (2) critical thinking bersifat reflektif dan evaluatif; (3) critical thinking merupakan konsep yang secara keseluruhan meliputi pandangan epistemologis, transformatif, dialektika dan holistik (Mogensen, 1997). Dari 
critical thinking dalam pendidikan lingkungan, siswa diharapkan dapat menalar dan menilai, sehingga mengarahkan mereka untuk melakukan apa yang harus dilakukan, harus dikembangkan dan dihasilkan terkait lingkungan.

Pendidikan lingkungan saat ini menjadi fokus perhatian teoretis dan praktis banyak ilmiah dan keprihatinan tentang berbagai masalah lingkungan telah membawa pendidikan lingkungan ke pusat opini publik. Pendidikan lingkungan sebagai salah satu jawaban dari permasalahan lingkungan memiliki banyak tantangan. Tantangan tersebut antara lain pengintegrasian sumber informasi terbaru secara efektif, kesempatan belajar yang luas, dan komunikasi efektif dari isu lingkungan kepada masyarakat (Hudson, 2001). Firth (1998) dalam (Bjorkland \& Pringle, 2001) berpendapat bahwa pendidikan lingkungan yang ada saat ini masih bersifat soft dan terkendala dengan komunikasi isu lingkungan kepada publik yang masih belum efektif. Firth menyarankan bahwa pendidikan paling efektif jika digabungkan dengan penemuan atau discovery. Pendidikan lingkungan lebih bukan sekadar studi tentang alam, konservasi, atau pengelolaan sumber daya, namun pembelajaran berbasis pengalaman, menggunakan semua sumber daya manusia, alam, dan fisik sekolah dan masyarakat sebagai laboratorium pendidikan (Bell, 2019). Hal ini akan meningkatkan kesadaran, penghargaan, pemahaman, dan motivasi siswa, memberi mereka keterampilan yang dibutuhkan untuk mempertahankan atau untuk mengubah ekosistem menjadi lebih baik.

Belajar berbasis pengalaman, siswa akan belajar menemukan, mengevaluasi, dan menimbang solusi terhadap isu lingkungan yang mungkin daripada sekadar belajar dan menerima satu pendekatan atau solusi tertentu. Pendidikan lingkungan yang berlangsung di rumah, sekolah, dan masyarakat memberi setiap orang kesempatan untuk melakukan pemecahan masalah yang realistis.

United Nations Decade of Education for Sustainable menyampaikan nilai-nilai mendasar yang harus dipromosikan oleh pendidikan untuk pembangunan berkelanjutan meliputi: penghormatan terhadap martabat dan hak asasi manusia semua orang di seluruh dunia dan komitmen terhadap keadilan sosial dan ekonomi untuk semua; menghormati hak asasi manusia generasi mendatang dan komitmen terhadap tanggung jawab antargenerasi, menghormati dan memelihara komunitas kehidupan yang lebih besar dalam semua keanekaragamannya, yang melibatkan perlindungan dan pemulihan ekosistem bumi; dan menghargai keanekaragaman budaya dan komitmen untuk membangun budaya toleransi, tanpa kekerasan dan perdamaian, baik 
secara lokal maupun global (Columbia Ministry of Education, n.d.).

Oleh karena itu PBB dengan visi tersebut menekankan pendekatan holistik, interdisipliner untuk mengembangkan pengetahuan dan keterampilan yang dibutuhkan untuk masa depan yang berkelanjutan, serta perubahan yang diperlukan dalam nilai-nilai manusia, perilaku, dan gaya hidup.

\section{Pendidikan Lingkungan Berbasis Experiential Learning}

\section{Integrasi Experiential Learning dalam Pendidikan Lingkungan}

Salah satu pendidikan lingkungan yang efektif adalah yang diintegrasikan dalam pembelajaran dan berbasis experiential learning. Experiential learning atau pembelajaran eksperimental ini lahir dari teori Kolb. Pembelajaran eksperimental melibatkan proses aktif dan terarah yang dikontekstualisasikan dalam kegiatan 'real worlds' langsung atau disimulasikan di mana siswa memiliki kesempatan untuk membangun dan mengatur pembelajaran pribadi dan profesional mereka sendiri.

Kolb (1984) dalam (Husin, 2013) menyatakan bahwa proses pengalaman adalah semua hal tentang apa yang telah kita lakukan, rasakan, sulit dan bahagia, cinta dan keyakinan, tujuan, hasrat, nikmati, lihat, kepercayaan, bayangkan, dll. Pengalaman dapat didefinisikan sebagai tindakan yang menghasilkan, menciptakan, dan menemukan pengetahuan untuk efek di masa depan. Isi pengalaman adalah "apa” yang kita alami. Kondisi pengalaman adalah "bagaimana” kita alami. John Dewey (1938) dalam (Breunig, 2017) membedakan pengalaman primer dan sekunder. Pengalaman primer adalah kegiatan atau keterlibatan insidentil. Pengalaman sekunder adalah menjalani proses penyelidikan reflektif teregulasi yang terintegrasi dengan pengalaman masa lalu dan dalam pertimbangan pengalaman masa depan dengan cara teleologis (terarah).

Experiential learning juga disebut sebagai belajar melalui tindakan, belajar dengan melakukan, melalui pengalaman, dan belajar melalui penemuan dan eksplorasi. Pembelajaran pengalaman adalah filosofi dan metodologi dimana pendidik sengaja terlibat dengan siswa dalam pengalaman langsung dan refleksi terfokus untuk meningkatkan pengetahuan, mengembangkan keterampilan, dan memperjelas nilai-nilai (Husin, 2013).

Experiential learning memberi kesempatan siswa untuk mengalami konsep secara langsung, dengan demikian memberi siswa pemahaman yang lebih 
kaya, lebih bermakna. Ini terjadi baik ketika siswa terlibat dalam memecahkan masalah yang merupakan bagian dari kegiatan dan ketika mereka menganalisis, berbagi, berdiskusi, dan merefleksikan reaksi pribadi mereka. Ini dapat secara signifikan meningkatkan memori siswa untuk konsep-konsep sejauh informasi disimpan dalam memori otobiografi. Experiential learning memiliki kemampuan untuk membentuk kepercayaan siswa tentang belajar dan tentang diri (Kolb \& Kolb, 2017).

Psikolog pendidikan seperti John Dewey (1859-1952), Carl Rogers (19021987), dan David Kolb (1984) telah memberikan landasan teori pembelajaran yang berfokus pada "belajar melalui pengalaman" atau "belajar dengan melakukan". Elemen kunci experiential learning yaitu siswa dengan tempat pembelajaran itu terjadi. Tempat pembelajaran pengalaman sebagai proses pembelajaran. Esensi dari pembelajaran pengalaman yang merupakan fase mengalami (melakukan), refleksi dan penerapan. Selain itu, tahapan refleksi dan penerapan adalah apa yang membuat pengalaman belajar berbeda dan lebih kuat daripada model yang biasa disebut sebagai "belajar sambil bekerja" atau "pembelajaran langsung" (Husin, 2013). Prinsip pembelajaran pengalaman yaitu refleksi, analisis kritis, dan sintesis, siswa mengambil inisiatif, membuat keputusan dan bertanggung jawab atas hasil, dalam proses pembelajaran siswa aktif.

Pembelajaran sederhana berpengaruh oleh pengalaman primer (indera) dan sekunder (dimediasi). Berdasarkan siklus Kolb pada Gambar 1, belajar terus menerus memiliki empat tahap yang berbeda. Dalam memulai siklus dapat dimulai dari tahap mana saja, namun semua tahap harus diselesaikan. Tahap 'Concrete Experience' dan 'Forming Abstract Concept' merupakan input informasi baik dari pengalaman maupun dari abstraksi sedangkan dua tahap lainnya 'Observation and Reflection' dan 'Active Experimentation' membutuhkan refleksi pada pengalaman, bersama dengan saran untuk tindakan di masa depan. berdasarkan hasil refleksi (Rosier et al., 2016).

Pendidikan lingkungan sangat erat terkait dengan experiential learning. Metode yang digunakan dalam pendidikan lingkungan akan lebih tepat sasaran jika menggunakan metode studi kasus, eksperimen, latihan lapangan, simulasi, kunjungan, debat, proyek, permainan peran dan inkuiri terbimbing memfasilitasi pembelajaran dan mendukung siswa dalam memahami masalah dunia nyata (Koutsoukos, Fragoulis, \& Valkanos, 2015). Selain itu, experiential learning memfasilitasi siswa membuka indera mereka untuk alam dan ikatan dengan alam, untuk meningkatkan penerimaan mereka terhadap realitas 
lingkungan. Seytiap sudut sekolah, mulai dari kelas hingga halaman dapat menjadi sumber belajar pendidikan lingkungan berbasis experiential learning.

Menghubungkan pendidikan lingkungan dengan experiential learning adalah upaya strategis membangun sistem pembelajaran seumur hidup yang mendorong partisipasi dalam pengalaman belajar dan melibatkan individu dalam pengalaman dunia nyata yang otentik. Integrasi experiential learning dalam pendidikan lingkungan bertujuan untuk:

a) mengintegrasikan pemikiran lingkungan ke dalam kehidupan seharihari siswa, menginstal nilai-nilai lingkungan

b) mendorong siswa untuk memperoleh cara berpikir yang baru

c) mengembangkan kolaborasi guru dan siswa

d) meningkatkan keterampilan pemecahan masalah siswa

e) meningkatkan keterampilan sosial

f) meningkatkan literasi ilmiahdan literasi lingkungan.

g) memungkinkan pengembangan keterampilan seperti kepercayaan diri, kemandirian, dan kemandirian siswa dan meningkatkan sikap positif terhadap pembelajaran

h) memahami lebih baik dunia alam dan masalah lingkungan jika mereka bekerja secara langsung dengan fenomena alam, menggunakan indera mereka untuk mengamati dan terlibat dalam pembelajaran pengalaman untuk memperluas kekuatan indera mereka (Koutsoukos et al., 2015).

Maloof (2006) dalam (Koutsoukos et al., 2015) menyampaikan bahwa pendidikan lingkungan berbasis experiential learning secara luas telah diterima, metode ini tampaknya lebih tepat, lebih efektif dan lebih bermanfaat bagi siswa.

Pendidikan lingkungan berbasis experiential learning berarti menanamkan siklus belajar Kolb dalam pembelajaran. Pendidikan lingkungan berbasis experiential learning mampu mengembangkan kemampuan siswa untuk merefleksikan sebelum, selama dan setelah pembelajaran lingkungan, sehingga memiliki keterampilan dalam mengambil keputusan dalam bertindak prolingkungan. Dalam pendidikan lingkungan ini, pengetahuan lingkungan akan dilengkapi dengan pengalaman berinteraksi dengan alam. Experiential learning memungkinkan siswa untuk membuat hubungan antara teori dan dunia nyata (Rosier et al., 2016). Siswa berinteraksi dengan lingkungan, dengannya mendapatkan pengalaman tentang lingkungan, sehingga merangsang motivasi mereka untuk belajar tentang lingkungan. Dalam experiential learning siswa 
diperkenalkan dengan peran perencana dalam proses pembuatan rencana (Rosier et al., 2016), sehingga pendidikan lingkungan dengan pendekatan ini akan memberikan bekal bagi siswa untuk dapat merancang tindakan prolingkungan atau menyusun solusi permasalahan lingkungan.

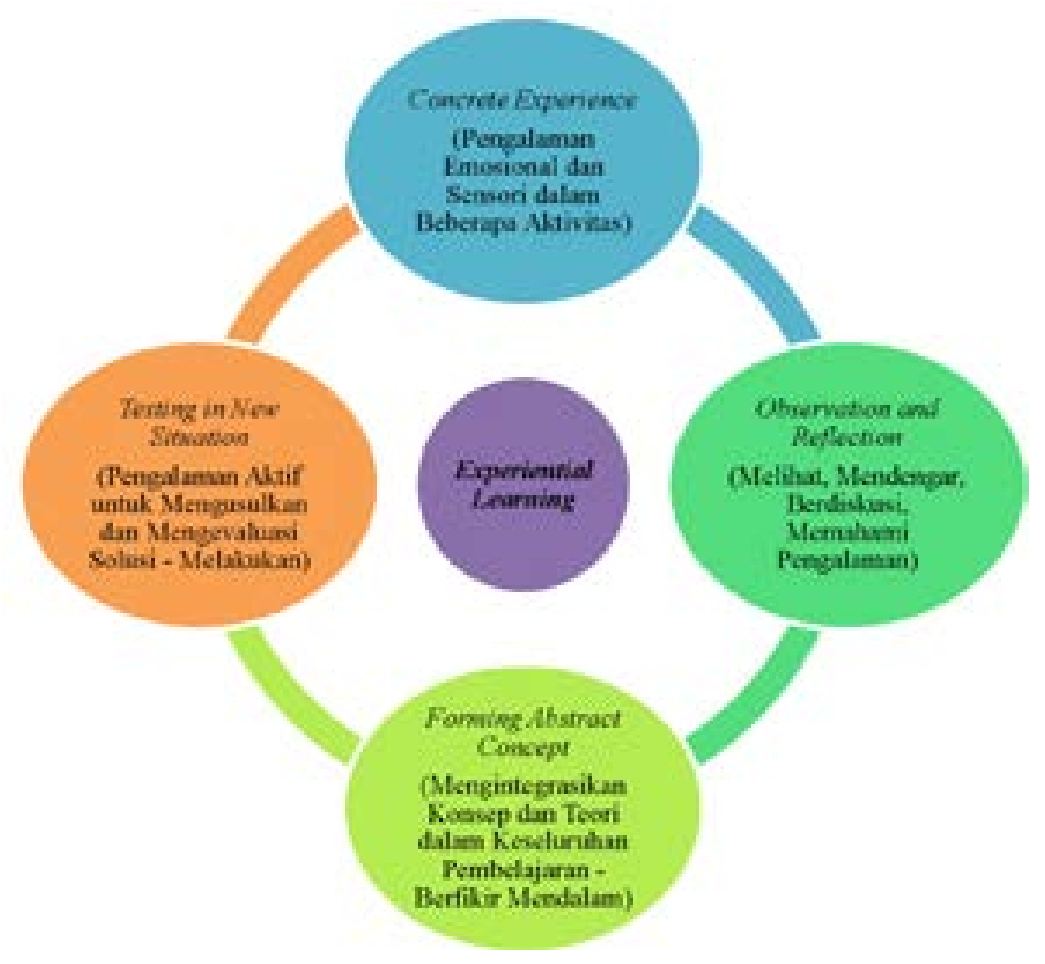

Gambar 1. Siklus Experiential Learning Kolb (Rosier et al., 2016)

Oleh karena itu pengalaman terhadap lingkungan juga dapat memberikan wawasan tentang karir potensial dan jaringan dengan rekan masa depan, mengembangkan hubungan profesional, meningkatkan kemampuan kerja, dan mengembangkan kesadaran sosial. Hasil interaksi siswa dengan permasalahan lingkungan akan membantu menumbuhkan kesadaran akan pentingnya lingkungan. Kotval (2003) dalam (Rosier et al., 2016) menyampaikan bahwa experiential learning juga mampu mengembangkan ketrampilan penting, seperti seni komunikasi, penyajian, pembelajaran mandiri, bekerja dengan orang lain dan pemecahan masalah. 


\section{Peran Pendidik}

Pendidik, guru, orang tua, maupun fasilitator pendidikan lingkungan berperan membuat perencanaan interaksi siswa dengan alam, komunitas, atau profesional yang berkaitan dengan pengetahuan ekologis atau permasalahan lingkungan. Hal ini memiliki manfaat langsung dan tidak langsung, seperti memberikan kontribusi kepada lingkungan dan masyarakat serta disiplin ilmu melalui proyek-proyek khusus yang dilakukan oleh siswa (Rosier et al., 2016). Kegiatan pendidikan lingkungan berbasis experiential learning juga dapat berbasis komunitas, seperti proyek di mana masyarakat berpartisipasi dalam pengelolaan atau pemulihan ekosistem lokal (Kalas \& Raisinghani, 2019).

Seorang guru dapat mengidentifikasi situasi yang menantang siswa melalui pemecahan masalah, kerja sama, kolaborasi, penemuan diri, dan refleksi diri. Pada saat yang sama, putuskan apa yang harus dipelajari atau diperoleh siswa dari pengalaman belajar.

Di bawah ini adalah beberapa poin utama untuk dipertimbangkan ketika mengintegrasikan pengalaman belajar dalam pengajaran (Husin, 2013):

a. Plan, merencanakan pengalaman dari tujuan pembelajaran dan menentukan aktivitas yang diperlukan siswa.

b. Prepare, menyiapkan dan memastikan kebutuhan sebelum pengalaman dimulai, seperti bahan dan alat penilaian.

c. Facilitate, membimbing siswa dalam proses menemukan, membangun pengetahuan, dan menentukan solusi

d. Evaluate, mengevaluasi untuk mengetahui sejauh mana kegiatan pembelajaran pengalaman memberi manfaat bagi siswa dan perbaikan pembelajaran pengalaman di masa depan.

\section{Metode Efektif melalui Fieldtrip dan Outdoor}

Salah satu metode efektif dalam pendidikan lingkungan berbasis experiential learning adalah dengan studi lapangan atau fieldtrip. Seperti kata pepatah, "travel is the best education". Perjalanan mampu menanamkan pendidikan nilai rasional. Perjalanan diyakini menumbuhkan pertumbuhan pencerahan, memperluas wawasan, dan memperkaya pengetahuan tentang sejarah, budaya, dan komunitas (Yang \& Lau, 2019). Pendidikan berbasis lapangan penting untuk disiplin ilmu perilaku, ekologi, evolusi, sistematika, sains, dan ilmu konservas. (Fleischner et al., 2017).

Ekologis Paul Dayton (2011) dalam (Fleischner et al., 2017) "there is simply 
no substitute for actually experiencing nature, to see, smell, and listen to the integrated pattern that nature offers an open mind". Studi lapangan berfungsi sebagai landasan dan pengalaman lapangan memaksa pengamat untuk mempertanyakan dan mengevaluasi kembali asumsi mereka tentang bagaimana dunia alami beroperasi. Pengamatan lapangan mengarah pada konstruksi hipotesis formal untuk menjelaskan fenomena alam. Siswa yang terlibat dalam pengalaman lapangan memiliki kesempatan lebih besar untuk memupuk koneksi kritis dari konsep abstrak menjadi realitas nyata. Studi lapangan memicu "sense of wonder" yang dapat meluncurkan siswa pada discovery based science. Pengalaman seperti ini dapat mengarah pada interaksi antara afektif dan kognitif, sehingga memberikan jembatan untuk pembelajaran tingkat tinggi atau high order learning (Fleischner et al., 2017).

Penelitian ini menunjukkan bahwa pendidikan lingkungan dapat efektif jika dilakukan di luar ruangan atau outdoor learning (Szczytko et al., 2018) particularly when little time is available for evaluation. Since environmental literacy (EL, demikian pula experiential learning sangat menyarankan siswa mendapatkan pengalaman di luar kelas. Pembelajaran berbasis pengalaman merupakan bentuk pembelajaran yang berbeda dengan pembelajaran di kelas tradisional (Kolb, 2014) dalam (Yang \& Lau, 2019), pembelajaran berbasis pengalaman menekankan pada aktivitas kontekstual dan pengalaman sensorik sebagai sumber belajar utama. Kolb (2014) dalam (Yang \& Lau, 2019) menyampaikan bahwa pengetahuan diciptakan melalui transformasi pengalaman. Penelitian Ballantyne, Packer, \& Falk (2011) dalam (Yang \& Lau, 2019) bahkan menegaskan bahwa pengalaman di tempat secara substansial menimbulkan perubahan positif dalam pengetahuan, sikap dan perilaku. Keterlibatan aktif di lokasi mendorong pengembangan dan perluasan pengetahuan, dan menghasilkan hasil belajar yang positif untuk anak-anak(Yang \& Lau, 2019). Dengan demikian pendidikan lingkungan dengan membawa siswa ke lingkungan alami akan lebih bermakna.

Palmberg dan Kuru (2000) mempelajari aktivitas perkemahan untuk siswa berusia 11-12 di Finlandia. Kegiatan yang ditawarkan di kamp adalah: kano, hiking, berlayar, dll. Para siswa juga tidur di tenda-tenda yang mereka pasang di hutan selama kamp. Para peneliti fokus pada kepekaan lingkungan di kalangan siswa dengan memanfaatkan metodologi kualitatif. Mereka menemukan bahwa ketika pengetahuan lingkungan dan sikap siswa meningkat, mereka cenderung memiliki empati terhadap lingkungan alam di sekitar mereka - tetapi perspektif siswa terhadap alam umumnya egosentris. Haskell (2000) berpartisipasi dalam 
program pendidikan petualangan luar ruang di Kanada dengan siswa sekolah menengah ke 8. Dia mencoba menentukan pengetahuan perseptual dalam pengalaman luar ruang siswa. Pada akhir program, siswa menjelaskan bahwa dia merasa terhubung dengan lingkungan alam.

Martin (2004) meneliti efektivitas kegiatan petualangan di luar ruangan pada hubungan yang dibangun oleh siswa dengan alam. Dia mempelajari siswa 11 dan 12 tahun yang berpartisipasi dalam $\mathrm{k}$ studi lingkungan outdoor di Bendigo, Australia. Pada akhir kursus siswa mengembangkan resonansi emosional dengan lingkungan alami. Ozdemir (2010) meneliti keefektifan program outdoor dalam pendidikan lingkungan pada perspektif lingkungan siswa kelas 6 dan 7 di Turki. Program ini mencakup topik-topik seperti: daur ulang, keanekaragaman hayati, habitat, dekomposisi dan penggunaan sumber daya alam. Ozdemir menemukan bahwa tingkat kecemasan siswa meningkat di akhir program dan siswa merasakan kedekatan emosional dengan lingkungan (Okur-Berberoglu, 2017). Dalam penelitian-penelitian tersebut, program pendidikan yang mereka fokuskan adalah outdoor learning, dengan demikian dapat disimpulkan bahwa pendidikan lingkungan melalui aktivitas outdoor dapat memberikan dampak positif hubungan siswa dengan alam.

Berinteraksi dengan lingkungan lokal mampu mengembangkan hubungan lebih dekat dengan alam dan memiliki kecenderungan untuk melindungi alam. Pengalaman di luar ruangan memungkinkan siswa untuk melihat organisme in situ dan mendapatkan pemahaman yang lebih baik tentang landscape terkait, tanaman dan hewan yang menghuninya, dan berbagai proses yang berbeda memengaruhi dan menghubungkan mereka (Jose et al., 2017). Kossack \& Bogner (2012) dalam (Jose et al., 2017) menyampaikan bahwa pengalaman lapangan luar ruangan satu hari memiliki efek positif pada pengetahuan dan sikap dan rasa terhubung dengan alam. Cara terbaik guru kelas untuk mengembangkan hubungan antara siswa dan alam adalah membawa siswa keluar dan melakukan kunjungan lapangan yang berfokus pada menghubungkan individu dengan lingkungan lokal mereka. Penelitian menunjukkan bahwa kegiatan dimana siswa dan pendidik berinteraksi selama pengalaman lapangan luar mendorong ingatan dan penerapan pengetahuan dengan cara baru. Interaksi emosional, fisik, dan sosial yang terjadi selama pengalaman di luar ruangan dapat mempromosikan ingatan dan perolehan pengetahuan baru yang secara langsung berhubungan kembali dengan pengalaman sebelumnya (Jose et al., 2017) 


\section{Proses Belajar Siswa}

Experiential learning membenamkan siswa dalam pengalaman dan mendorong refleksi pribadi yang memupuk keterampilan, sikap, atau cara berpikir baru. Tujuan pendidikan bagi siswa untuk secara bebas terlibat dalam pengalaman belajar mereka sendiri, bekerja untuk mengeksplorasi solusi dan memahami dunia secara mandiri. Siswa kemudian terlibat dengan orang lain di komunitas untuk merefleksikan pengalaman mereka, menerima bimbingan, dan menunjukkan apa yang mereka yakini telah mereka pelajari secara lebih terbuka (Kalafatis, Neosh, Libarkin, Whyte, \& Caldwell, 2019). Oleh karena itu, salah satu cara belajar adalah dengan melakukan (learning by doing). Siswa mengalami pengalaman berkaitan dengan lingkungan dan kemudian mengeksplorasi solusi permasalahan lingkungan.

Experiential learning merupakan bagian dari pendekatan konstruktivis. Individu memiliki pengalaman konkret dan kemudian menggunakan kognisi aktif mereka sendiri untuk secara sengaja meningkatkan pengetahuan (Fenwick 2001) dalam (Kalafatis et al., 2019). Individu mencari kontinuitas antara pengalaman masa lalu dan masa kini, sehingga keputusan pribadi akan menjaga kontinuitas baik dengan menolak informasi baru atau untuk memperbarui pemahaman sebelumnya. Pengalaman siswa berinteraksi dengan lingkungan atau terpapar permasalahan lingkungan akan dikonstruk dalam memori dan mempengaruhi keputusan pro-lingkungan siswa.

Refleksi memainkan peran kunci dalam pendidikan lingkungan berbasis experiential learning. Refleksi sebagai proses di mana individu menganalisis pengalaman mereka untuk mendapatkan pengetahuan darinya. Refleksi dalam experiential learning digambarkan sebagai proses perbandingan di mana individu menjadi sadar akan suatu masalah dan kemudian mempertimbangkan cara terbaik untuk mencapai tujuan yang ditentukan secara rasional (Kalafatis et al., 2019). Emosi dan indera perasa fisik memiliki peran dalam refleksi karena sensasi tubuh seseorang memengaruhi respons mereka. Hasil refleksi pengalaman dengan permasalahan lingkungan akan mempengaruhi tindakannya terhadap lingkungan.

Berikut merupakan urutan proses belajar siswa dalam pendidikan lingkungan berbasis experiential learning menurut Diem (2011) dalam (Husin, 2013):

\section{a. Experiencing/Exploring "Doing"}

Siswa melakukan pengalaman langsung dengan atau tanpa 
bantuan guru berkaitan dengan ekologi atau permasalahan lingkungan. Aspek kunci dari pengalaman belajar adalah apa yang siswa pelajari dari pengalaman daripada kuantitas atau kualitas pengalaman.

b. Sharing/Reflecting "What Happened?"

Siswa membagikan hasil pengalaman dengan temannya, mendapatkan teman sebaya untuk berbicara tentang pengalaman mereka sendiri, dan mendiskusikan perasaan yang dihasilkan dari pengalamannya.

c. Processing/Analyzing "What's Important?"

Siswa menganalisis dan merefleksikan pengalaman, memungkinkan siswa menghubungkannya dengan pengalaman belajar di masa depan. Hasil refleksi ini akan menentukan pandangan dan tindakannya terhadap lingkungan.

d. Generalizing "So What?"

Siswa menghubungkan pengalaman dengan contoh dunia nyata, menemukan tren atau kebenaran umum dalam pengalaman, dan mengidentifikasi prinsip "real worlds" yang muncul.

e. Application "Now What?"

Siswa akan menerapkan apa yang mereka pelajari dalam pengalaman ke situasi yang serupa atau berbeda. Selain itu, siswa akan membahas bagaimana proses yang baru dipelajari dapat diterapkan pada situasi lain.

\section{Pendidikan Lingkungan Berbasis Experiential Learning}

Dalam penelitian tentang pendidikan lingkungan ini dapat peneliti sampaikan beberapa saran yang cukup penting untuk kegiatan pendidikan lingkungan berbasis experiential learning (Columbia Ministry of Education, n.d.).

a. mendorong integrasi mata pelajaran/pendekatan multidisiplin, pendidikan lingkungan dapat dipandang sebagai contoh pembelajaran lintas-kurikuler atau terpadu.

b. mendorong refleksi kritis pada berbagai perspektif, pendidikan menyediakan berbagai perspektif dan sudut pandang. Penting untuk menyediakan alat untuk berpikir kritis dan menganalisis masalah dari berbagai perspektif 
c. memberikan paparan masalah yang berkaitan dengan lingkungan, penting untuk tetap update dan meminta siswa terlibat dengan masalah yang terkait dengan komunitas mereka.

d. mempelajari tentang isu-isu lingkungan, Pengetahuan Ekologis Tradisional Masyarakat Pertama dari bentang alam, wilayah atau ekologi tertentu dapat menjadi komponen penting dari pendidikan lingkungan yang tepat dan responsif secara budaya.

e. mengakui perspektif lain dan ada beragam perspektif tentang lingkungan. Penting bahwa perspektif budaya dan agama lainnya diakui, dihormati dan dianalisis dalam hal implikasinya terhadap masalah.

f. mempertimbangkan tempat pengalaman tindakan, penting bagi siswa untuk memahami berbagai cara di mana tindakan dapat terjadi dan konsekuensi dari tindakan tersebut terhadap lingkungan.

g. mempertimbangkan isu-isu dari perspektif lokal dan global. Tindakan yang diambil di tingkat lokal memiliki konsekuensi global yang juga harus dipertimbangkan ketika membuat keputusan.

Berikut ini contoh aktivitas pendidikan lingkungan berbasis experiential learning dengan tema "Manusia dan Lingkungan" (Husin, 2013)

a. Siswa dihadapkan dengan lingkungan yang terdiri atas komponen biotik dan abiotik.

b. Siswa melihat, mendengar, menyentuh, merasakan, meneliti bendabenda yang ditemui dari komponen biotik dan abiotik

c. Guru bertanya kepada siswa apa yang dapat mereka sampaikan dan temui

d. Guru memberi siswa kesempatan untuk melaporkan apa yang telah mereka dapatkan melalui 5 indera dan apa yang telah ia lakukan pada objek.

e. Guru bertanya kepada siswa apa yang terjadi dengan temuannya, kemudian mengundang siswa untuk berdiskusi melalui kelompok yang telah dibentuk.

f. Guru bertanya kepada juru bicara kelompok dan membantu anggota tentang apa yang telah ia alami pada objek, kemudian siswa meminta untuk berbagi dengan anggota kelompok lainnya (refleksi).

g. Hasil diskusi mengambil pelajaran dari hal-hal yang telah dialami oleh 
objek

h. Siswa merumuskan dalam bahasa sederhana

i. Siswa yang terlihat terakhir menerapkan perolehan pengetahuan, sikap, dan keterampilan pada siswa

\section{Kesimpulan}

Pendidikan lingkungan berbasis experiential learning merupakan metode efektif dalam menanamkan literasi lingkungan. Pendidikan lingkungan berbasis experiential learning berarti menanamkan siklus belajar Kolb dalam pembelajaran yang mengintegrasikan pendidikan lingkungan. Siklus Kolb terdiri atas: (1) Concrete Experience; (2) Observation and Reflection; (3) Forming Abstract Concept; (4) Testing in New Situation. Pendidikan lingkungan berbasis experiential learning akan memberikan bekal bagi siswa untuk dapat merancang tindakan prolingkungan atau menyusun solusi permasalahan lingkungan.

\section{Daftar Pustaka}

Aman, A., Sudrajat, A., Yuliana, L. (2018) Effectiveness of social problem solving model in improving social skills of transvestites in the special regions Yogyakarta. Journal of Social Studies (JSS), 14 (1). 1-12. https://doi. org/10.21831/jss.v14i1.21159.

Arianto, H. (2017). Urgensi Perlindungan Ekosistem Laut Terhadap Bahaya Ilegal Fishing. Lex Jurnalica, 14(3), 184-191.

BAPPENAS. (2004). Wilayah Kritis Keanekaragaman Hayati Di Indonesia: 77. https://doi.org/ 10.2147/DHPS.S74410

BAPPENAS. (2016). Indonesia Biodiversity Startegy and Action Plan (IBSAP) 2012. 2020.

Bjorkland, R., \& Pringle, C. M. (2001). Educating Our Communities and Ourselves about Conservation of Aquatic Resources through Environmental Outreach. BioScience, 51(4), 279. https://doi.org/10.1641 /00063568(2001)051[0279:eocaoa]2.0.co;2

Breunig, M. (2017). Experientially Learning and Teaching in a Student-Directed Classroom. 1-18. https://doi.org/10.1177/1053825917690870

Columbia Ministry of Education. (n.d.). Environmental Learning And Experience An interdisciplinary guide for teachers. British Columbia. 
Fleischner, T. L., Espinoza, R. E., Gerrish, G. A., Greene, H. W., Kimmerer, R. W., Lacey, E. A., ... Zander, L. (2017). Teaching Biology in the Field: Importance, Challenges, and Solutions. BioScience, 67(6), 558-567. https://doi.org/10.1093/biosci/bix036

Gough, Annette, and Gough, N. (2015). Environmental education. In Sage Publications (In Kridel,). https://doi.org/10.1080/00219266.1993.9655 340

Granit-Dgani, D., Kaplan, A., \& Flum, H. (2017). Theory-based assessment in environmental education: a tool for formative evaluation. Environmental Education Research, 23(2), 269-299. https://doi.org/10.1080/13504622 .2016 .1144172

Husin, A. (2013). Implementation Of Experiential Learning Methods On Environmental Lesson For Elementary School. 1st SEA-DR Proceeding, 42-49. Palembang: Sriwijaya University.

Jose, S., Patrick, P. G., Moseley, C., Jose, S., Patrick, P. G., \& Moseley, C. (2017). Experiential learning theory: the importance of outdoor classrooms in environmental education. 8455(August). https://doi.org/10.1080/215484 55.2016.1272144

Kalafatis, S. E., Neosh, J., Libarkin, J. C., Whyte, K. P., \& Caldwell, C. (2019). Experiential Learning Processes Informing Climate Change Decision Support. Weather, Climate, and Society, 11(3), 681-694. https:// doi. org/10.1175/wcas-d-19-0002.1

Kalas, P., \& Raisinghani, L. (2019). Assessing the Impact of Community-Based Experiential Learning: The Case of Biology 1000 Students. International Journal of Teaching and Learning in Higher Education, 31(2), 261-273.

Kolb, A. Y., \& Kolb, D. A. (2017). Experiential Learning Theory as a Guide for Experiential Educators in Higher Education. A Journal for Engaged Educators, 1(1), 7-44.

Koutsoukos, M., Fragoulis, I., \& Valkanos, E. (2015). Connection of Environmental Education with Application of Experiential Teaching Methods: A Case Study from Greece. 8(4), 23-28. https://doi.org/10.5539/ ies.v8n4p23

Mogensen, F. (1997). Critical thinking: A central element in developing action competence in health and environmental education. Health Education Research, 12(4), 429-436. https://doi.org/10.1093/her/12.4.429

Okur-Berberoglu, E. (2017). Outdoor Experiential Environmental Education : 
Humanika, Kajian IImiah Mata Kuliah Umum, Vol. 20. No. 1. (2020), 63-82

An Adult-Centred Intervention for the Affective Domain. International Electronic Journal of Environmental Education, 7(1), 34-58.

Portal, W. M. Y. (n.d.). Experiential Learning in Environmental Education Par. In Environmental Education Teaching Strategy (pp. 1-3). Retrieved from www.pjse.ca

Purba, N. P., Handyman, D. I. W., Pribadi, T. D., Syakti, A. D., Pranowo, W. S., Harvey, A., \& Ihsan, Y. N. (2019). Marine debris in Indonesia : A review of research and status. Marine Pollution Bulletin, 146(March), 134-144. https://doi.org/10.1016/j.mar polbul. 2019.05.057

RIEEA. (2016). Rhode Island K - 12 Env ironmental Literacy Assessment Plan. Rhode Island Environmental Education Association.

Rosier, J., Slade, C., Perkins, T., Baldwin, C., Coiacetto, E., Budge, T., \& Harwood, A. (2016). The benefits of embedding experiential learning in the education of planners. Planning Practice and Research, 31(5), 486-499. https://doi.org/10.1080/0269 7459. 2016.1229899

Stehli, F. G. and, \& Wells, J. W. (2014). Diversity and age patterns in hermatypic corals. Systematic Zoology, 20(2), 115-126. https://doi. org/10.2307/2412052

Szczytko, R., Stevenson, K., Peterson, M. N., Nietfeld, J., \& Strnad, R. L. (2018). Development and validation of the environmental literacy instrument for adolescents. Environmental Education Research, 4622, 1-18. https:// doi.org/10.1080/ 13504622. 2018.1487035

Tessnow-von Wysocki, I., \& Le Billon, P. (2019). Plastics at sea: Treaty design for a global solution to marine plastic pollution. Environmental Science and Policy, 100(June), 94-104. https:// doi.org/10.1016/j.envsci.2019.06.005

Uar, N. D., Murti, S. H., \& Hadisusanto, S. (2016). Kerusakan Lingkungan Akibat Aktivitas Manusia Pada Ekosistem Terumbu Karang. Majalah Geografi Indonesia, 30(1), 88. https://doi.org/10.22146/mgi.15626

Yang, F. X., \& Lau, V. M. C. (2019). Experiential learning for children at World Heritage Sites: The joint moderating effect of brand awareness and generation of Chinese family travelers. Tourism Management, 72(June 2018), 1-11. https://doi.org/ 10.1016/j.tourman. 2018.11.011 